\title{
Cytokine storm and colchicine potential role fighting SARS-CoV-2 pneumonia
}

\author{
Antonio Vitiello ${ }^{1}$, Francesco Ferrara ${ }^{2}$, Giovanni Granata ${ }^{3}$, and Raffaele La Porta ${ }^{4}$ \\ ${ }^{1}$ Azienda Unità Sanitaria Locale Umbria 1 \\ ${ }^{2}$ USL 1 Umbria \\ ${ }^{3}$ Local Health Authority Salerno \\ ${ }^{4}$ ASUR Marche
}

April 28, 2020

\begin{abstract}
For some patients with SARS-CoV-2, the worst clinical damage is not caused by the virus itself, but by an overactive inflammatory state. In fact, in some people the immune system goes into overdrive and launches a large-scale assault on the tissue known as cytokine storm. This excessive immune reaction can damage tissue and eventually kill people. Several tests show that blocking such cytokine storms can be effective, studies are underway to test drugs that act by reducing cytokine response, such as tocilizumab and sarilumab that bind interleukin 6 (IL-6) or anikinra which is the interleukin 1 receptor antagonist (IL-1). However, other drugs that block the cytokine cascade can also be considered. In this article we describe the scientific and molecular motivation for the use of drugs that act by modulating the inflammatory system in patients with SARS-CoV-2, considering in particular an old drug that has been in use for many years for other therapeutic indications such as colchicine, and that could be favorable its use to block the cytokine cascade in SARS-CoV-2 patients, with low cost and good tolerability.
\end{abstract}

\section{Hosted file}

Cythokine storm and colchicine role fighting SarsCov2 pneumonia great.pdf available at https: //authorea.com/users/310208/articles/444910-cytokine-storm-and-colchicine-potential-rolefighting-sars-cov-2-pneumonia 